This article is licensed under the Creative Commons Attribution-NonCommercial 4.0 International License (CC BY-NC) (http://www.karger.com/Services/OpenAccessLicense). Usage and distribution for commercial purposes requires written permission.

\title{
Association of Optic Nerve Head Drusen with Best Vitelliform Macular Dystrophy: A Case Series
}

\author{
Robert J. White Daniel J. Watson Dara D. Koozekanani \\ Sandra R. Montezuma \\ Department of Ophthalmology and Visual Neurosciences, University of Minnesota, \\ Minneapolis, MN, USA
}

\section{Keywords}

Best vitelliform macular dystrophy · Best disease - Optic nerve head drusen

\begin{abstract}
Purpose: To report the association of optic nerve head $(\mathrm{ONH})$ drusen with Best vitelliform macular dystrophy (BVMD). Methods: Chart review. Patients: Five patients from 3 families. Results: Multimodal imaging and ophthalmic examination demonstrated findings consistent with $\mathrm{ONH}$ drusen, in association with BVMD, in 5 patients. Conclusion: We report the association of BVMD with ONH drusen in 5 patients. This combination has previously been reported only once. We recommend that patients with a diagnosis of BVMD undergo autofluorescence and ultrasound imaging of the optic nerve to help facilitate this diagnosis, as some $\mathrm{ONH}$ drusen can be buried.




\section{Case Reports in Ophthalmology}

White et al.: Association of Optic Nerve Head Drusen with Best Vitelliform Macular Dystrophy: A Case Series

\section{Introduction}

Optic nerve head $(\mathrm{ONH})$ drusen are deposits of hyaline calcific material that are often asymptomatic and discovered incidentally on ophthalmologic examination. The overall prevalence is between 0.4 and $3.7 \%$, although a 10 -fold increase in prevalence is seen among family members [1]. The pattern of inheritance is believed to be autosomal dominant with incomplete penetrance; however, this has not been verified $[1,2]$. The pathogenesis of $\mathrm{ONH}$ drusen is unknown, although it is believed to be related to dysplasia and crowding of the $\mathrm{ONH}$ and its blood supply. Current theories postulate that dysplasia may result in a disturbance of axonal metabolism and transport. Axons may rupture and release mitochondria into the extracellular space, which may serve as nidi for drusen formation [3]. Congenital abnormalities in the $\mathrm{ONH}$ vasculature may additionally contribute by allowing protein transudation and subsequent deposition of extracellular materials.

In a study of 27 relatives of 7 probands with bilateral ONH drusen, Antcliff and Spalton [2] noted the presence of an abnormal vasculature in around $50 \%$ of individuals, and additionally noted disc crowding in around $50 \%$ of individuals. However, the combination of disc crowding and an abnormal vasculature was observed in only $30 \%$ of these patients. They concluded that $\mathrm{ONH}$ drusen were not likely the manifestation of a single gene mutation, but rather a complex phenomenon, with inherited dysplasia of the optic disc being the primary predisposition.

Best vitelliform macular dystrophy (BVMD) is an autosomal dominant condition with onset typically in childhood and gradual progression into adulthood. The disease locus has been mapped to chromosome 11q12-13 and encodes for a calcium-activated chloride channel located in the retinal pigment epithelium (RPE) (BEST1; formerly VMD2). It is proposed that ionic homeostasis caused by dysfunction of this ion channel, bestrophin-1, results in a weakened interface between the RPE and photoreceptors [4]. This dysfunction could subsequently result in the accumulation of retina-derived pigment. Virtually all patients with familial BVMD demonstrate mutations in BEST1, with Kramer et al. [5] having noted a mutation in BEST1 in $96 \%$ of patients with familial BVMD. Its diagnosis is based on electrooculography (EOG), examination of the fundus, and family history. The most meaningful finding from EOG is the Arden ratio, which is a measure of the ratio of the light peak to the dark trough. A reduced value of less than 1.5 is observed in BVMD. Choroidal neovascular membranes (CNVM) may be present in later stages of the disease.

$\mathrm{ONH}$ drusen have previously been reported in association with various ocular and systemic diseases. In particular, an increased frequency of optic disc drusen is observed with retinitis pigmentosa, pseudoxanthoma elasticum, and Alagille syndrome [6]. We describe a case series of ONH drusen in patients with BVMD (Table 1), a phenomenon which to our knowledge has been reported on only one previous occasion thought to be an incidental finding. 


\section{Case Reports in Ophthalmology}

White et al.: Association of Optic Nerve Head Drusen with Best Vitelliform Macular Dystrophy: A Case Series

\section{Cases}

Case 1

A 54-year-old father with a known diagnosis of BVMD confirmed by EOG done 10 years prior by an outside provider presented with his 3 children. His eye examination had been stable over several years, with a visual acuity of 20/15 to 20/20 OD and 20/70 to 20/80 eccentrically OS. His anterior segment examination was unremarkable. On fundus examination, his optic nerves appeared crowded with blurring of the disc margins. There appeared to be an increase in vasculature branching. There were focal areas of yellow subretinal deposits along the vascular arcades OU. The macula OD showed RPE changes. The macula OS had central atrophy (Fig. 1a, b). The periphery of both eyes demonstrated dot-blot hemorrhages consistent with his known diagnosis of moderate diabetic retinopathy. Optical coherence tomography (OCT) demonstrated stable focal areas of subretinal fluid OU and macular atrophy OS. In addition, a thick choroid with large vessels was noted OU. Fundus autofluorescence (FAF) demonstrated $\mathrm{ONH}$ drusen $\mathrm{OU}$ and mottled hypoautofluorescence in both maculas and in areas corresponding to the yellow subretinal deposits OU (Fig. 2a, b).

\section{Case 2}

The 22-year-old son of our first patient had also been diagnosed with BVMD with a progressive course at the age of 6 years by an outside provider. He had no other past medical issues. The examination results had been stable, with vision 20/30 to 20/50 OD and 20/50 to 20/70 OS. His pupils, intraocular pressure values, and slit lamp examination results were normal OU. The fundus examination was significant for slightly elevated ONH with blurred margins OU. Both maculas demonstrated atrophic changes with signs of old regressed CNVM. He had a fibrous scar OS from the fovea toward the ONH (Fig. 1c, d). OCT demonstrated macular scarring with increased subretinal hyperreflectivity and stable subretinal fluid versus lucency. Previous fluorescein angiography had demonstrated staining of the macula scarring OU. FAF revealed ONH drusen OS and central foveal hypoautofluorescence OU. Initial EOG was unreliable due to artifacts; this was not pursued further due to a family history and initial appearance on examination characteristic of BVMD. The patient deferred genetic testing.

\section{Case 3}

The 16-year-old daughter of the first patient had been diagnosed with BVMD at 5 years of age affecting only the left eye. She had no other medical issues. Her vision OS had been $20 / 40$ to $20 / 30$ until the age of 12 years, when her vitelliform lesion began to scramble. Until the time of presentation, her vision had remained stable at 20/15 to 20/20 OD but declined to $20 / 50$ to $20 / 60$ OS. Her anterior segment examination was normal. The fundus examination was significant for elevated $\mathrm{ONH}$ with blurred margins. There appeared to be an increase in retinal vasculature branching, more OS than OD. The macula OS demonstrated pigment mottling and early atrophy surrounding a central vitelliform elevation (Fig. 1e, f). Initial B-scan ultrasound confirmed the evidence of ONH drusen OD only (Fig. 3a). Subsequent FAF demonstrated ONH drusen OU (Fig. 2c, d). Of note, another member of family 1, a fraternal twin sister, carries the diagnosis of $\mathrm{ONH}$ drusen confirmed by both B-scan and FAF, although she has had no signs of BVMD to date. 


\section{Case Reports in Ophthalmology}

White et al:: Association of Optic Nerve Head Drusen with Best Vitelliform Macular Dystrophy: A Case Series

\section{Case 4}

A 22-year-old man with a known diagnosis of BVMD diagnosed by an outside provider presented to establish care. His other ocular history was significant for secondary glaucoma, requiring a glaucoma shunt OS. His family history was significant for BVMD in the patient's father, paternal grandmother, and great grandmother, although notably none of the family members were known to have $\mathrm{ONH}$ drusen. The patient's visual acuity had been stable at $20 / 50$ to $20 / 60$ OD and 20/80 to 20/100 OS. His pupil examination was significant for an afferent pupillary defect OS. His intraocular pressures had ranged from the low 20 s to mid10s. The slit lamp examination was unremarkable OD and OS demonstrated a superotemporal tube shut with a $3+$ posterior subcapsular cataract. The fundus examination revealed ONH with blurred margins OD and an increased cup-to-disc ratio to $0.7 \mathrm{OS}$. His fundus examination revealed significant atrophic macular changes $\mathrm{OU}$, with the left eye having a large arteriovenous malformation connecting to the area of atrophy thought to be secondary to old CNVM from his vitelliform lesion. There appeared to be an increase in retinal vasculature branching OD (Fig. 1g, h). A B-scan and FAF confirmed the presence of ONH drusen OU (Fig. 2e, f, 3b, c). OCT demonstrated hyperreflective subfoveal lesions bilaterally. Fluorescein angiography showed bilateral macular scarring staining without leakage. There was venous filling of the arteriovenous malformation connecting to macular scar but no active CNVM. The patient declined genetic testing.

Case 5

A 38-year-old woman with a history of BVMD diagnosed at the age of 6 years presented for follow-up. Her family history was significant for BVMD in her father and sister. Her vision was 20/60 OU with no improvement on pinhole examination. Her anterior segment examination result was unremarkable. On fundoscopy, her optic nerves were relatively small, crowded, and with slight blurring of the nasal disc margins. Her fundus examination revealed a subfoveal fibrotic scar OD and macular RPE atrophy OS (Fig. 1i, j). OCT showed subfoveal hyperreflective lesions consistent with old regressed CNVM, and stable subretinal fluid OU. FAF demonstrated ONH drusen and macular hypoautofluorescence OU (Fig. 2g, h). A B-scan demonstrated ONH drusen OU (Fig. 3d, e). The patient declined genetic testing.

\section{Discussion}

To our knowledge, the only previous case of $\mathrm{ONH}$ drusen in association with presumed BVMD was reported in 1975 by Benson et al. [7]. The diagnosis of BVMD was made by a clinical diagnosis of bilateral vitelliform lesions, although notably this patient did not have genetic testing or EOG. The patient was a 9-year-old child whose family history unfortunately was unknown as the patient was adopted. The authors noted that they believed the coexistence of these conditions to be coincidental.

Although a coincidental relationship between the conditions is certainly possible, we open for discussion the possibility that BVMD predisposes individuals to having $\mathrm{ONH}$ drusen. The role of bestrophin- 1 as a protein with a transmembrane domain in the RPE is of interest, as drusen are known to form during RPE destabilization. In one theory, drusen for- 


\section{Case Reports in Ophthalmology}

Case Rep Ophthalmol 2018;9:76-86

DOI: $10.1159 / 000485963$

(c) 2018 The Author(s). Published by S. Karger AG, Basel www.karger.com/cop

White et al.: Association of Optic Nerve Head Drusen with Best Vitelliform Macular Dystrophy: A Case Series

mation begins with inflammation and subsequent loss of RPE cells. This loss in the epithelial barrier allows for retinal drusen accumulation [8].

$\mathrm{ONH}$ drusen, in association with retinitis pigmentosa and microphthalmos, have been reported in a case series of patients with dysfunction of membrane frizzled-related protein (MFRP), which, like bestrophin-1, is expressed in the RPE and contains a transmembrane domain. Won et al. [9] concluded that MFRP plays a wider role in eye development than previously suspected, not only functioning as a regulator of axial eye length but also having a photoreceptor maintenance role during retinal development. Due to the fact that bestrophin- 1 contains a transmembrane domain in the RPE, we question if the protein plays a role in membrane stabilization, among other functions in ocular development.

Vincent et al. [10] described the spectrum of phenotypic characteristics of BEST1related autosomal dominant vitreoretinochoroidopathy in a family with a p.V86M mutation. Autosomal dominant vitreoretinochoroidopathy is a slowly progressive vitreoretinal degeneration with significant intra-familial phenotypic variability, including optic nerve dysplasia, microcornea, a shallow anterior chamber, and iris dysgenesis. BEST1 is proposed to have a role in normal ocular development in this condition. $\mathrm{ONH}$ drusen were not reported by Vincent et al. [10], and, likewise, we did not observe optic nerve dysplasia, microcornea, or a shallow anterior chamber in our patients. However, our patients had crowded optic nerves, and 4 of them appeared to have increased retinal vasculature branching, findings previously noted in increased frequency among patients with $\mathrm{ONH}$ drusen. We argue that these differences could be attributed to phenotypic variability in the BEST1 gene. Of further interest is the theory that $\mathrm{ONH}$ drusen are a by-product of ONH dysplasia. This would open a discussion of the role of BEST1 in ocular development and could potentially explain the association of BVMD with ONH drusen in our patients. Further investigation including genetic testing is needed to better understand if any correlation may exist between the two conditions. Also, of note, our patients had relatively advanced stages of Best disease, indicating a possible relationship between the presence of $\mathrm{ONH}$ drusen and advanced stages of Best disease.

Our case series is limited in that no genetic testing was performed, since the patients were not interested in having this test. Genetic testing could help understanding this potential association, given that both conditions could be inherited in an autosomal dominant fashion. Since some patients can have buried ONH drusen, which are difficult to identify on examination, we recommend that clinicians perform FAF imaging and ultrasound on patients with a diagnosis of BVMD to help facilitating the diagnosis of this association.

Additionally, we mentioned a member of family 1, a fraternal twin sister, who carries the diagnosis of $\mathrm{ONH}$ drusen but who had no signs of BVMD on her most recent examination at 16 years of age. This could weaken the argument that BVMD contributes to the formation of $\mathrm{ONH}$ drusen. Unfortunately, we were unable to follow this patient to monitor for early signs of BVMD, and so we are unable to accurately comment on whether or not this patient currently possesses the disease. Previous studies have shown that the age at onset and disease severity are highly variable among patients with BVMD, even among family members, and that the age at onset may be as late as the 6th decade of life $[11,12]$. This patient potentially could be monitored with EOG, as previous studies have demonstrated abnormal EOG findings in light of a normal fundus examination in some heterozygous carriers [13]; however, EOG results are not always abnormal in patients with BVMD [14]. Genetic testing would 
White et al.: Association of Optic Nerve Head Drusen with Best Vitelliform Macular Dystrophy: A Case Series

be ideal to determine if the patient carries the same mutation but manifests a different phenotype or late presentation of BVMD.

It is important to be aware of this association, as $\mathrm{ONH}$ drusen can be present with visual field defects, anterior ischemic optic neuropathy because of crowding of the optic nerve and axon compression, and peripapillary CNVM. In addition, knowing of this association could help to avoid unnecessary neurological workup in young patients that present with visual loss and pseudo-disc edema [15].

\section{Acknowledgments}

Funds in support of our study come from a Lions Research Grant and an unrestricted grant from Research to Prevent Blindness.

\section{Statement of Ethics}

The subjects have given their informed consent. The study protocol has been approved by the institute's committee on human research.

\section{Disclosure Statement}

All authors state that they have no conflicts of interest to disclose.

\section{References}

Davis PL, Jay WM: Optic nerve head drusen. Semin Ophthalmol 2003;18:222-242.

Antcliff RJ, Spalton DJ: Are optic disc drusen inherited? Ophthalmology 1999;106:1278-1281.

Lam BL, Morais CG Jr, Pasol J: Drusen of the optic disc. Curr Neurol Neurosci Rep 2008;8:404-408.

Hartzell HC, Qu Z, Yu K, et al: Molecular physiology of bestrophins: multifunctional membrane proteins linked to Best disease and other retinopathies. Physiol Rev 2008;88:639-672.

5 Krämer F, White K, Pauleikhoff D, et al: Mutations in the VMD2 gene are associated with juvenile-onset vitelliform macular dystrophy (Best disease) and adult vitelliform macular dystrophy but not agerelated macular degeneration. Eur J Hum Genet 2000;8:286-292.

6 Chang MY, Pineles SL: Optic disk drusen in children. Surv Ophthalmol 2016;61:745-758.

7 Benson WE, Kolker AE, Enoch JM, et al: Best's vitelliform macular dystrophy. Am J Ophthalmol 1975;79:59-66.

8 Strauss 0: The retinal pigment epithelium in visual function. Physiol Rev 2005;85:845-881.

-9 Won J, Smith RS, Peachey NS, et al: Membrane frizzled-related protein is necessary for the normal development and maintenance of photoreceptor outer segments. Vis Neurosci 2008;25:563-574.

10 Vincent A, McAlister C, Vandenhoven C, Héon E: BEST1-related autosomal dominant vitreoretinochoroidopathy: a degenerative disease with a range of developmental ocular anomalies. Eye (Lond) 2011;25:113-118.

11 Boon CJ, Klevering BJ, Leroy BP, et al: The spectrum of ocular phenotypes caused by mutations in the BEST1 gene. Prog Retin Eye Res 2009;28:187-205.

12 Lacassagne E, Dhuez A, Rigaudière F, et al: Phenotypic variability in a French family with a novel mutation in the BEST1 gene causing multifocal Best vitelliform macular dystrophy. Mol Vis 2011;17:309-322. 
13 Piñeiro-Gallego T, Álvarez M, Pereiro I, et al: Clinical evaluation of two consanguineous families with homozygous mutations in BEST1. Mol Vis 2011;17:1607-1617.

14 Wabbels B, Preising MN, Kretschmann U, et al: Genotype-phenotype correlation and longitudinal course in ten families with Best vitelliform macular dystrophy. Graefes Arch Clin Exp Ophthalmol 2006;244:1453-1466.

15 Sahin A, Cingü AK, Ari S, et al: Bilateral optic disc drusen mimicking papilledema. J Clin Neurol 2012;8:151-154. 


\section{Case Reports in Ophthalmology}
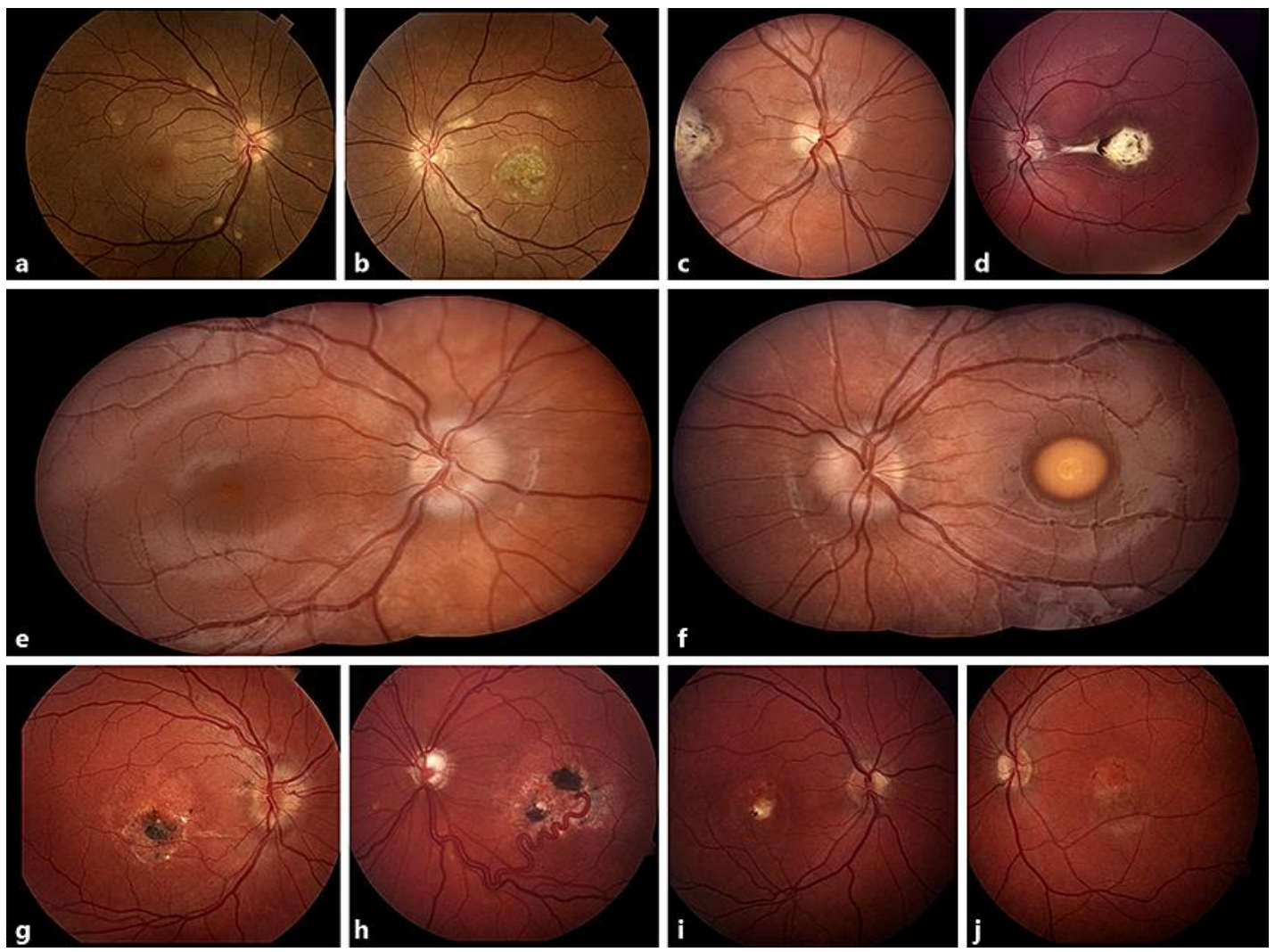

Fig. 1. Fundus photographs. a, b Images from a 54-year-old man (case 1) with BVMD which demonstrate elevated optic nerves with mild blurring of the margins OU and focal areas of subretinal deposits along the vascular arcades OU as well as macular atrophy OS. c, d Images from the 22-year-old son of case 1 (case 2), also with BVMD, demonstrating elevated optic nerves with mild blurring of the margins and atrophic maculas OU with signs of old regressed CNVM and a fibrous scar extending from the fovea to the ONH OS. e, $\mathbf{f}$ Images from the 16-year-old daughter of case 1 (case 3), demonstrating elevated optic nerves and moderate blurring of the margins with a vitelliform macular lesion OS. $\mathbf{g}$, $\mathbf{h}$ Images from a 22-year-old man (case 4), demonstrating an elevated $\mathrm{ONH}$ with blurred margins and a severely glaucomatous optic nerve OS. The patient also has atrophic maculas OU with a dilated and tortuous draining vein with chorioretinal anastomosis thought to be secondary to an old CNVM from his vitelliform lesion OS. $\mathbf{i}$, $\mathbf{j}$ Images from a 38-year-old woman (case 5), demonstrating elevated optic nerves with blurred margins OU, a subfoveal fibrotic scar OD, and macular RPE atrophy OS. BVMD, Best vitelliform macular dystrophy; ONH, optic nerve head; CNVM, choroidal neovascular membrane; RPE, retinal pigment epithelium. 


\section{Case Reports in Ophthalmology}
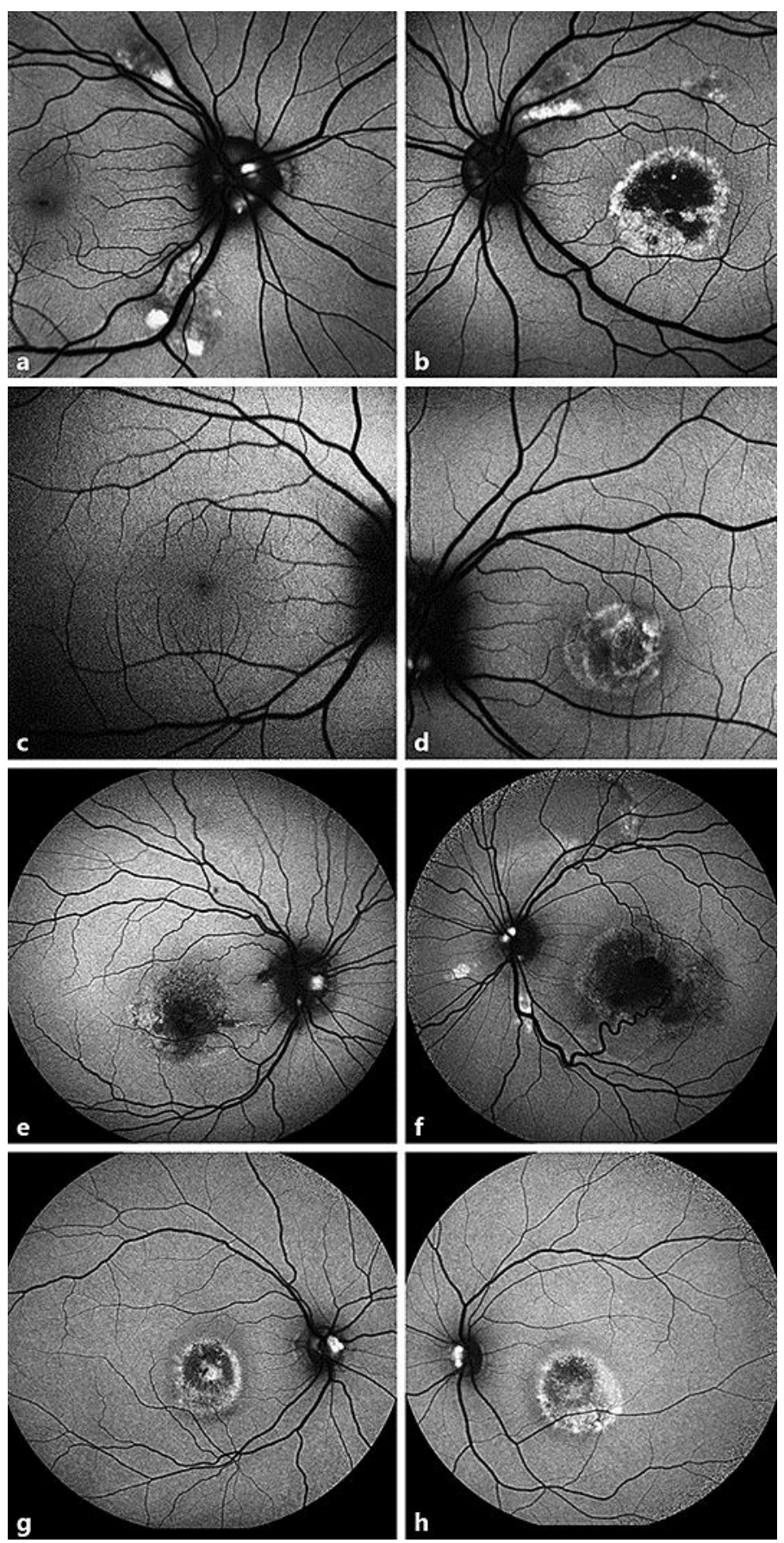

Case Rep Ophthalmol 2018;9:76-86

(C) 2018 The Author(s). Published by S. Karger AG, Basel www.karger.com/cop

White et al:: Association of Optic Nerve Head Drusen with Best Vitelliform Macular

Dystrophy: A Case Series 


\section{Case Reports in Ophthalmology}

\begin{tabular}{l|l}
\hline Case Rep Ophthalmol 2018:9:76-86 \\
\hline DOI: 10.1159/000485963 & $\begin{array}{l}\text { @ } 2018 \text { The Author(s). Published by S. Karger AG, Basel } \\
\text { www.karger.com/cop }\end{array}$ \\
\hline
\end{tabular}

White et al.: Association of Optic Nerve Head Drusen with Best Vitelliform Macular Dystrophy: A Case Series

Fig. 2. Fundus autofluorescence photographs. a, b Images from a 54-year-old man (case 1), demonstrating ONH drusen OU and mottled hypoautofluorescence in both maculas and in areas along the vascular arcades corresponding to yellow subretinal deposits OU (see Fig. 1a, b). c, d Images from a 16-year-old female (case 2), demonstrating ONH drusen OU with central hypo-/hyperautofluorescence centrally OS. e, f Images from a 22-year-old man (case 4), demonstrating ONH drusen OU and mottled hypoautofluorescence in both maculas. $\mathbf{g}$, $\mathbf{h}$ Images from a 38-year-old woman, demonstrating ONH drusen and macular hypoautofluorescence OU. ONH, optic nerve head.
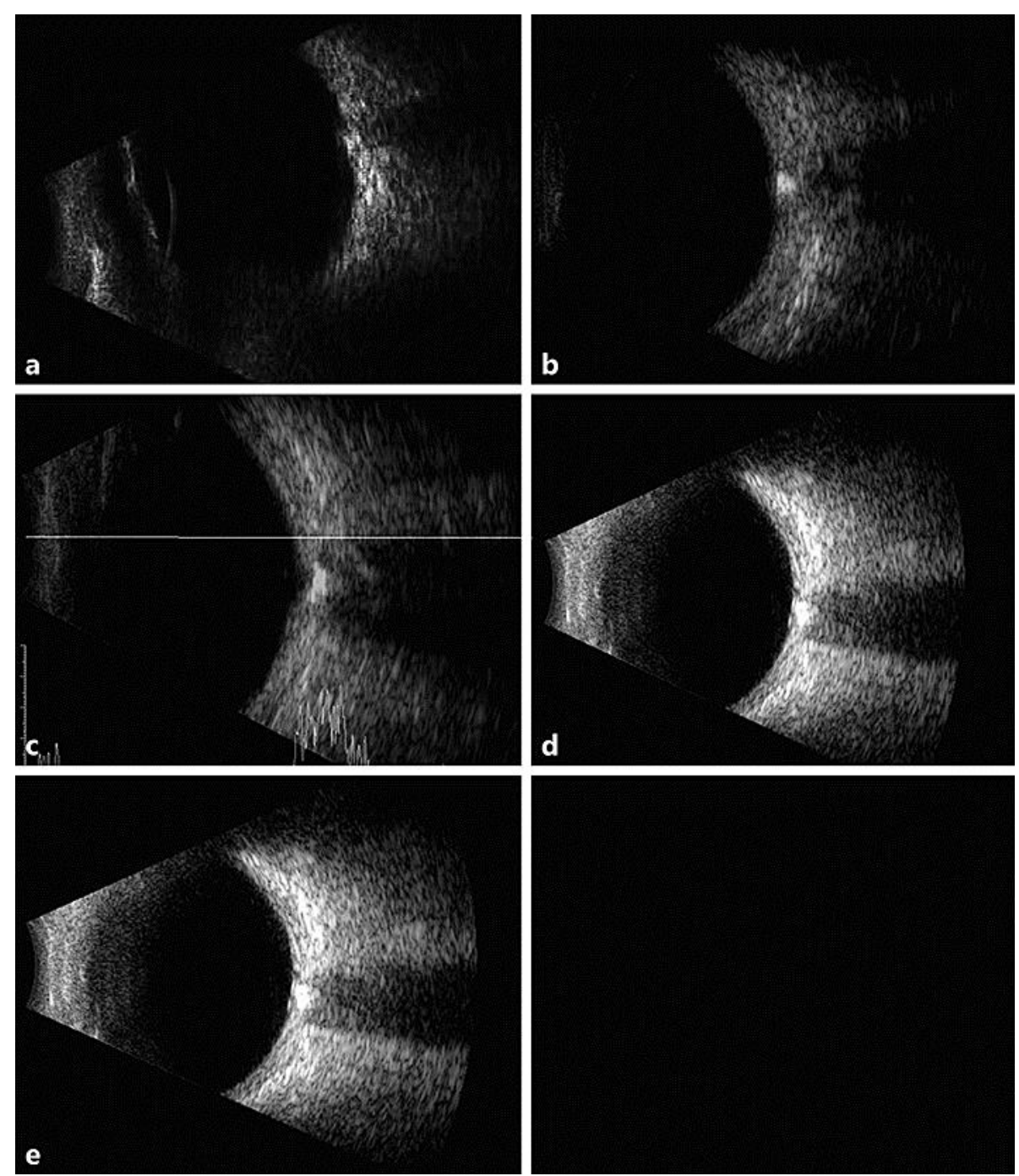

Fig. 3. B-scans demonstrating calcification and posterior shadowing from $\mathrm{ONH}$ drusen in a 16-year-old girl (a; case 3, OD), a 22-year-old man (b, c; case 4, OD and OS, respectively), and a 38-year-old woman (d, e; case 5, OD and OS, respectively). ONH, optic nerve head. 
White et al.: Association of Optic Nerve Head Drusen with Best Vitelliform Macular Dystrophy: A Case Series

Table 1. Clinical history, examinations, and advanced testing of 5 reported patients with a history of BVMD and ONH drusen

\begin{tabular}{|c|c|c|c|c|c|c|c|c|c|}
\hline $\begin{array}{l}\text { Patient; } \\
\text { family, } \\
\text { No. }\end{array}$ & $\begin{array}{l}\text { Age, } \\
\text { years; } \\
\text { gender }\end{array}$ & Family history & Visual acuity & $\begin{array}{l}\text { Fundoscopic } \\
\text { examination }\end{array}$ & $\begin{array}{l}\text { Optical coherence } \\
\text { tomography }\end{array}$ & $\begin{array}{l}\text { Fundus } \\
\text { autofluorescence }\end{array}$ & $\begin{array}{l}\text { Fluorescein } \\
\text { angiography }\end{array}$ & $\begin{array}{l}\text { Electro- } \\
\text { oculogram }\end{array}$ & $\begin{array}{l}\text { B-scan } \\
\text { ultrasound }\end{array}$ \\
\hline $1 ; 1$ & $54 ; \mathrm{M}$ & \multirow{3}{*}{$\begin{array}{l}\text { Fraternal twin } \\
\text { sister of patient } 3 \\
\text { with ONH drusen } \\
\text { confirmed by } \\
\text { B-scan and FAF } \\
\text { in the absence of } \\
\text { BVMD }\end{array}$} & $\begin{array}{l}20 / 15-20 / 20 \text { OD } \\
\text { and } 20 / 70-20 / 80 \\
\text { OS; stable for several } \\
\text { years }\end{array}$ & See Fig. 1a, b & $\begin{array}{l}\text { Stable focal areas of } \\
\text { subretinal fluid OU, } \\
\text { macular atrophy OS, thick } \\
\text { choroid and large vessels } \\
\text { OU }\end{array}$ & $\begin{array}{l}\text { ONH drusen OU } \\
\text { and macular } \\
\text { hypoautofluores- } \\
\text { cence (Fig. 2a, b) }\end{array}$ & Not performed & $\begin{array}{l}\text { By outside } \\
\text { provider, } \\
\text { suggestive of } \\
\text { BVMD }\end{array}$ & $\begin{array}{l}\text { Not } \\
\text { performed }\end{array}$ \\
\hline $2 ; 1$ & $22 ; \mathrm{M}$ & & $\begin{array}{l}20 / 30-20 / 50 \text { OD } \\
\text { and } 20 / 50-20 / 70 \\
\text { OS; stable for several } \\
\text { years }\end{array}$ & See Fig. 1c, d & $\begin{array}{l}\text { Macular scarring with } \\
\text { increased subretinal } \\
\text { hyperreflectivity and } \\
\text { stable subretinal fluid } \\
\text { versus lucency }\end{array}$ & $\begin{array}{l}\text { ONH drusen OS and } \\
\text { central foveal hypo- } \\
\text { autofluorescence OU } \\
\text { (per report from } \\
\text { outside facility) }\end{array}$ & $\begin{array}{l}\text { Staining of } \\
\text { macular scarring } \\
\text { OU }\end{array}$ & $\begin{array}{l}\text { Unreliable } \\
\text { due to } \\
\text { artifacts }\end{array}$ & $\begin{array}{l}\text { Not } \\
\text { performed }\end{array}$ \\
\hline $3 ; 1$ & $16 ; \mathrm{F}$ & & $\begin{array}{l}\text { OD stable at } 20 / \\
15-20 / 20 \text {, OS slowly } \\
\text { declining to } 20 / \\
50-20 / 60\end{array}$ & See Fig. 1e, f & Not performed & $\begin{array}{l}\text { ONH drusen OU } \\
\text { (Fig. 2c, d) }\end{array}$ & Not performed & $\begin{array}{l}\text { Not } \\
\text { performed }\end{array}$ & $\begin{array}{l}\text { ONH drusen } \\
\text { OD (Fig. 3a) }\end{array}$ \\
\hline $4 ; 2$ & $22 ; \mathrm{M}$ & $\begin{array}{l}\text { Father, paternal } \\
\text { grandmother, great } \\
\text { grandmother with } \\
\text { BVMD }\end{array}$ & $\begin{array}{l}20 / 50-20 / 60 \text { OD } \\
\text { and } 20 / 80-20 / 100 \\
\text { OS; stable for years }\end{array}$ & See Fig. 1g, h & $\begin{array}{l}\text { Hyperreflective subfoveal } \\
\text { lesions OU }\end{array}$ & $\begin{array}{l}\text { ONH drusen } \mathrm{OU} \\
\text { (Fig. 2e,f) }\end{array}$ & $\begin{array}{l}\text { Bilateral macular } \\
\text { scarring staining } \\
\text { without leakage }\end{array}$ & $\begin{array}{l}\text { Not } \\
\text { performed }\end{array}$ & $\begin{array}{l}\text { ONH drusen } \\
\text { OU (Fig. 3b, c) }\end{array}$ \\
\hline $5 ; 3$ & $38 ; \mathrm{F}$ & $\begin{array}{l}\text { Father and sister } \\
\text { with BVMD }\end{array}$ & $\begin{array}{l}\text { 20/60 OU; stable for } \\
\text { years }\end{array}$ & See Fig. 1i, j & $\begin{array}{l}\text { Subfoveal hyperreflective } \\
\text { lesions consistent with } \\
\text { old regressed CNVM, and } \\
\text { stable subretinal fluid OU }\end{array}$ & $\begin{array}{l}\text { ONH drusen and } \\
\text { macular hypo- } \\
\text { autofluorescence OU } \\
\text { (Fig. } 2 \mathrm{~g}, \mathrm{~h} \text { ) }\end{array}$ & Not performed & $\begin{array}{l}\text { Not } \\
\text { performed }\end{array}$ & $\begin{array}{l}\text { ONH drusen } \\
\text { OU (Fig. 3d, e) }\end{array}$ \\
\hline
\end{tabular}

BVMD, Best vitelliform macular dystrophy; ONH, optic nerve head; FAF, fundus autofluorescence; CNVM, choroidal neovascular membrane. 